\title{
Kinetic Spectrophotometric Determination of Gemifloxacin Mesylate and Moxifloxacin Hydrochloride in Pharmaceutical Preparations Using 4-Chloro-7-nitrobenzo-2-oxa-1,3-diazole
}

\author{
Mohammed G. Abdel Wahed, Ragaa El Sheikh, Ayman A. Gouda, and Sayed Abou Taleb \\ Chemistry Department, Faculty of Science, Zagazig University, Zagazig 44519, Egypt \\ Correspondence should be addressed to Ayman A. Gouda; aymangouda77@gmail.com
}

Received 4 September 2013; Accepted 3 December 2013; Published 3 February 2014

Academic Editor: Adam F. Lee

Copyright (C) 2014 Mohammed G. Abdel Wahed et al. This is an open access article distributed under the Creative Commons Attribution License, which permits unrestricted use, distribution, and reproduction in any medium, provided the original work is properly cited.

\begin{abstract}
Simple, sensitive, and accurate kinetic spectrophotometric method was proposed for the determination of gemifloxacin mesylate (GMF) and moxifloxacin hydrochloride (MOX) in pure forms and pharmaceutical preparations (tablets). The method is based on coupling the studied drugs with 4-chloro-7-nitrobenzo-2-oxa-1,3-diazole (NBD-Cl) in the presence of alkaline borate buffer. Spectrophotometric measurement was achieved by recording the absorbance at 466 and $464 \mathrm{~nm}$ for GMF and MOX, respectively, after a fixed time of 20 and $15 \mathrm{~min}$ on a water bath adjusted at $70 \pm 5^{\circ} \mathrm{C}$ for both drugs. The different experimental parameters affecting the development and stability of the color were carefully studied and optimized. The absorbance-concentration plots were linear over the ranges $0.5-8.0$ and $2.0-12 \mu \mathrm{g} \mathrm{mL}^{-1}$ for GMF and MOX, respectively. The limit of detection of the kinetic method was about $0.12\left(2.47 \times 10^{-7} \mathrm{M}\right)$ and $0.36\left(8.22 \times 10^{-7} \mathrm{M}\right) \mu \mathrm{g} \mathrm{mL} \mathrm{L}^{-1}$ for GMF and MOX, respectively. The proposed methods have been applied and validated successfully with percentage relative standard deviation (RSD\% $\leq 0.52$ ) as precision and percentage relative error $(\mathrm{RE} \% \leq 1.33)$ as accuracy. The robustness of the proposed method was examined with recovery values that were $97.5-100.5$ $\pm 1.3-1.9 \%$. Statistical comparison of the results with the reference spectrophotometric methods shows excellent agreement and indicates no significant difference in accuracy or precision.
\end{abstract}

\section{Introduction}

Gemifloxacin mesylate (GMF) is (R,S)-7-[(4Z)-3-(aminomethyl)-4-(methoxyimino)-1-pyrrolidinyl]-1-cyclopropyl-6fluoro-1, 4-dihydro-4-oxo-1, 8-naphthyridine-3-carboxylic acid methanesulfonate, and moxifloxacin (MOX) is \{1-cyclopropyl-7-[2,8-diazobicyclo (4.3.0) nonane]-6-fluoro-8-methoxy-1, 4 dihydro-4-oxo-3-quinoline carboxylic acid\} (Scheme 1) [1]. GMF and MOX are broad-spectrum fluoroquinolone antibiotics that are active against both Gram-positive and Gram-negative bacteria [2]. The bactericidal activity of the drug is mediated by the inhibition of DNA gyrase (topoisomerase II) and topoisomerase IV, essential enzymes involved in bacterial DNA replication, transcription, repair, and recombination. GMF and MOX are antibiotics used to treat respiratory infections, including acute sinusitis, acute exacerbations of chronic bronchitis, and community-acquired pneumonia, as well as dermatological infections, as a secondline agent in tuberculosis. Due to their clinical advantages, GMF and MOX are receiving a great interest and there was an increase in number of their pharmaceutical dosage forms in the market in recent past. For routine analysis of the studied drugs, a simple, rapid, and cost-effective analytical method was required.

No official (pharmacopoeia) method has been found for the assay of GMF and MOX in their pharmaceutical formulations. Several methods have been reported on the determination of fluoroquinolones either in pure forms, in dosage forms, or in biological fluids like chromatography [3-6], capillary zone electrophoresis [7, 8], electrochemistry [9-11], atomic absorption spectrometry [12, 13], spectrofluorimetry [14-16], and spectrophotometric methods for GMF [17-28] or MOX [12, 29-36] (Tables 1 and 2). These methods were associated with some major drawbacks such as decreased 
<smiles>CO/N=C1\CN(c2nc3c(cc2F)c(=O)c(C(=O)O)cn3C2CC2)CC1SN</smiles>

Gemifloxacin mesylate (GMF)<smiles>COc1c(N2C[C@H]3CCCN[C@H]3[C@H]2C)c(F)cc2c(=O)c(C(=O)O)cn(C3CC3)c12</smiles>

Moxifloxacin $\mathrm{HCl}(\mathrm{MOX})$

SCHeme 1: The chemical structure of the studied drugs.

TABLE 1: Comparison between the reported spectrophotometric methods for determination of GMF.

\begin{tabular}{|c|c|c|c|c|}
\hline Reagent & $\lambda_{\max } \mathrm{nm}$ & $\begin{array}{l}\text { Concentration range } \\
\left(\mu \mathrm{g} \mathrm{mL}^{-1}\right)\end{array}$ & $\begin{array}{l}\text { Molar absorptivity } \\
\mathrm{L} \mathrm{mol}^{-1} \mathrm{~cm}^{-1}\end{array}$ & Reference \\
\hline UV spectrophotometry & 272 & $8-40$ & & [17] \\
\hline UV spectrophotometry & 267 & $10-70$ & & {$[19]$} \\
\hline Iodine & 290 & $6.0-30$ & $1.46 \times 10^{4}$ & \multirow{4}{*}[23]{} \\
\hline $\begin{array}{l}\text { 2,3-Dichloro-5, } \\
\text { 6-dicyano-p-benzoquinone (DDQ) }\end{array}$ & 470 & $2.0-10$ & $4.17 \times 10^{4}$ & \\
\hline $\begin{array}{l}\text { 7,7,8,8-Tetracyanoquinodimethane } \\
\text { (TCNQ) }\end{array}$ & 840 & $2.5-12.5$ & $3.42 \times 10^{4}$ & \\
\hline Tetracyanoethylene (TCNE) & 420 & $1.0-5.0$ & $8.41 \times 10^{4}$ & \\
\hline Safranin O & 525 & $3.0-15$ & $2.81 \times 10^{4}$ & \multirow{4}{*}[24]{} \\
\hline Methylene blue & 650 & $4.0-20$ & $2.20 \times 10^{4}$ & \\
\hline Naphthol blue 12BR & 620 & $2.0-10$ & $4.02 \times 10^{4}$ & \\
\hline Azocarmine G & 540 & $2.0-10$ & $4.15 \times 10^{4}$ & \\
\hline Folin-Ciocalteu/NaOH & 685 & $10-50$ & & {$[25]$} \\
\hline $\begin{array}{l}\text { 3-Methyl-2-benzothiazolinone } \\
\text { hydrazone } \mathrm{FeCl}_{3}\end{array}$ & 617 & $10-100$ & & \\
\hline $\mathrm{FeCl}_{3} / 1,10$-phenanthroline & 466 & $40-200$ & & \\
\hline Ninhydrine (DMF) & 590 & $4.0-32$ & $9.68 \times 10^{3}$ & \multirow{3}{*}[26]{} \\
\hline Ascorbic acid (DMF) & 530 & $8.0-40$ & $5.58 \times 10^{3}$ & \\
\hline p-benzoquinone (PBQ) & 400 & $9.0-72$ & $4.98 \times 10^{3}$ & \\
\hline Palladium/zero order & 430 & $2.0-14$ & $1.365 \times 10^{4}$ & \multirow{3}{*}[28]{} \\
\hline Palladium/1st derivative & 480 & $1.0-10$ & $9.37 \times 10^{4}$ & \\
\hline Palladium/2nd derivative & 500 & $1.0-15$ & $1.59 \times 10^{4}$ & \\
\hline NBD-Cl & 466 & $0.5-8.0$ & $4.0892 \times 10^{4}$ & Present work \\
\hline
\end{tabular}

selectivity due to measurement in ultraviolet region and/or decreased simplicity of the assay procedure (e.g., tedious precipitation or liquid-liquid extraction steps in the ionpair formation-based methods). For these reasons, it was worthwhile to develop a new simple and selective spectrophotometric method for the determination of the studied drugs in their pharmaceutical dosage forms.

Kinetic methods have certain advantages in pharmaceutical analysis regarding selectivity and elimination of additive interferences, which affect direct spectrophotometric methods. The literature is still poor in analytical assay methods based on kinetics for the determination of GMF and MOX in dosage forms. Furthermore, some specific advantages that the kinetic methods possess are as follows [37]:

(i) simple and fast methods because some experimental steps such as filtration and extraction are avoided prior to absorbance measurements;

(ii) high selectivity since they involve the measurement of the absorbance as a function of reaction time instead of measuring the concrete absorbance value;

(iii) other active compounds present in the commercial dosage forms may not interfere if they are resisting 
TABLE 2: Comparison between the previously mentioned spectrophotometric methods for determination of MOX.

\begin{tabular}{|c|c|c|c|c|}
\hline Reagent & $\lambda_{\max }(\mathrm{nm})$ & $\begin{array}{l}\text { Concentration range } \\
\left(\mu \mathrm{g} \mathrm{mL}^{-1}\right)\end{array}$ & $\begin{array}{l}\text { Molar absorptivity } \\
\mathrm{L} \mathrm{mol}^{-1} \mathrm{~cm}^{-1}\end{array}$ & Reference \\
\hline Ammonium reineckate & 525 & $100-1100$ & $1.075 \times 10^{3}$ & {$[12]$} \\
\hline UV spectrophotometry $\mathrm{HCl}(0.1 \mathrm{~N})$ & 295 & $2.0-25$ & & [30] \\
\hline UV spectrophotometry & 290 & $1.0-12$ & & {$[31]$} \\
\hline Crotonaldehyde/dichlone & 648 & $3.0-48$ & & \\
\hline Folin-Ciocalteu's $/ \mathrm{Na}_{2} \mathrm{CO}_{3}$ & 750 & $5.0-40$ & & \\
\hline \multicolumn{5}{|l|}{ UV spectrophotometry } \\
\hline $\mathrm{HCl}(0.1 \mathrm{~N})(\mathrm{pH} 1.2)$ & 296 & $1.0-12$ & $4.63 \times 10^{4}$ & [33] \\
\hline Phosphate buffer (pH 7.4) & 289 & $1.0-14$ & $4.08 \times 10^{4}$ & \\
\hline \multicolumn{5}{|c|}{ 2,3,5,6-Tetrachloro-1,4-benzoquinone/acetaldehyde } \\
\hline Initial rate & 652 & $5.0-100$ & & [34] \\
\hline Fixed time & 652 & $15-150$ & & \\
\hline Bromocresol green (BCG) & 415.8 & $2.0-20$ & & [35] \\
\hline $\mathrm{Fe}^{3+} / 1,10-$ phenanthroline & 510 & $0.8-6.0$ & $6.61 \times 10^{4}$ & \\
\hline $\mathrm{Fe}^{3+} / 2,2^{\prime}$ bipyridyl & 520 & $0.8-4.0$ & $8.5 \times 10^{4}$ & {$[36]$} \\
\hline Bismuth (III) tetraiodide & 462 & $16-96$ & $4.5 \times 10^{3}$ & \\
\hline NBD-Cl & 464 & $2.0-12$ & $3.48535 \times 10^{4}$ & Present work \\
\hline
\end{tabular}

the chemical reaction conditions established for the proposed kinetic method;

(iv) colored and/or turbid sample background may possibly not interfere with the determination process.

Therefore, there is a need for another kinetic approach to estimate the drug in commercial dosage forms. This paper describes a simple and sensitive kinetic spectrophotometric method for the determination of GMF and MOX in bulk and drugs formulations. 4-Chloro-7-nitrobenzo-2-oxa-1,3diazole (NBD-Cl) was selected as a derivatizing reagent because it forms chromogenic derivatives with primary or secondary amines requiring relatively mild reaction conditions. GMF and MOX contain primary and secondary amino groups, respectively, which are known to react with (NBD$\mathrm{Cl}$ ) in aqueous/acetone medium resulting in the formation of orange yellow color drug-NBD derivatives, which absorbs maximally at $\lambda_{\max } 466$ and $464 \mathrm{~nm}$ for GMF and MOX, respectively. The absorbance increases with time and therefore, two calibration procedures, that is, initial rate and fixedtime methods, are adopted for the determination of each drug in commercial dosage forms.

\section{Materials and Methods}

2.1. Apparatus. All absorption spectra were made using Kontron 930 (UV-Visible) spectrophotometer (German) with a scanning speed of $200 \mathrm{~nm} / \mathrm{min}$ and a band width of $2.0 \mathrm{~nm}$, equipped with $10 \mathrm{~mm}$ matched quartz cells.

2.2. Materials and Reagents. All chemicals were of analytical reagent grade and the solvents were of spectroscopic grade.
Pharmaceutical grade gemifloxacin mesylate (GMF) was supplied by Al-Obour Pharmaceutical \& Chemical Industries Company, Egypt, and its potency was $99.99 \pm 0.39 \%$. Moxifloxacin hydrochloride (MOX) reference standard was provided by Sabaa, Kahira Company, Egypt, and its purity was $100.01 \pm 0.707 \%$.

Pharmaceutical Preparations. All the following tablets were purchased from the commercial source in the local market. Factive tablets were obtained from Oscient Pharmaceuticals Corporation, USA; Flobiotic tablets were obtained from Hikma Pharm. \& Chem. Ind. Company, Egypt. GemiQue tablets were obtained from Obour Pharm. \& Chem. Ind. Company, Egypt, labeled to contain $320 \mathrm{mg}$ GMF per tablet. Avelox tables were obtained from Bayer, Germany, and Moxiflox tablets were obtained from EVA Pharm. \& Chem. Ind. Company, Egypt. Moxifloxacin tablets were obtained from Sabaa International Company for Pharmaceuticals and Chemical Industries, Egypt, labeled to contain 400 mg MOX per tablet.

Stock Solutions. Stock standard solutions of GMF and MOX $\left(100 \mu \mathrm{g} \mathrm{mL}^{-1}\right)$ were prepared by dissolving an exact weight $(10 \mathrm{mg})$ of the studied drugs in $2.0 \mathrm{~mL} 0.005 \mathrm{M} \mathrm{HCl}$ and further diluted to $100 \mathrm{~mL}$ with bidistilled water in a $100 \mathrm{~mL}$ measuring flask. These solutions also were found to be stable for at least one week without alteration when kept in the refrigerator.

Reagents. 4-Chloro-7-nitrobenzofurazan (NBD-Cl) (Fluka, Germany), a fresh solution $\left(5.0 \times 10^{-3} \mathrm{M}\right)$ in acetone, was prepared daily. Buffer solution was prepared as follows: $0.620 \mathrm{~g}$ boric acid and $0.75 \mathrm{~g}$ potassium chloride were dissolved with 
$100 \mathrm{~mL}$ of water and $\mathrm{pH}$ of 8.5 and 9.0 is adjusted only with $0.1 \mathrm{M}$ sodium hydroxide solution.

\subsection{Recommended General Procedures}

2.3.1. Rate Data Method. Aliquots of standard GMF $\left(100 \mu \mathrm{g} \mathrm{mL}^{-1}\right)(0.05-1.0 \mathrm{~mL})$ and MOX $\left(100 \mu \mathrm{g} \mathrm{mL}^{-1}\right)(0.2-$ $1.2 \mathrm{~mL}$ ) solutions were transferred into a series of $10 \mathrm{~mL}$ volumetric flasks. Then $0.4 \mathrm{~mL}$ of borate buffer solution was added followed by addition of 1.0 and $0.8 \mathrm{~mL}$ of $(5.0 \times$ $\left.10^{-3} \mathrm{M}\right) \mathrm{NBD}-\mathrm{Cl}$ solution for GMF and MOX, respectively, and the volume was made up to the mark with $50 \%(\mathrm{v} / \mathrm{v})$ aqueous acetone, mixed well, and heated on water bath at $70 \pm 5^{\circ} \mathrm{C}$. After mixing, the contents of each flask were completed to $10 \mathrm{~mL}$ with $50 \%(\mathrm{v} / \mathrm{v})$ aqueous acetone and immediately transferred to the spectrophotometric cell and the increase in absorbance was recorded at 466 and $464 \mathrm{~nm}$ GMF and MOX, respectively, as a function of time between 2.5-30 min against reagent blank treated similarly. The rate of the reaction $(v)$ at different concentrations was obtained from the slope of the tangent to the absorbance-time curve. The calibration curve was constructed by plotting the logarithm of the reaction rate $(\log v)$ versus the logarithm of the molar concentration of the drug $(\log C)$. The amount of the drug was obtained either from the calibration graphs or the regression equation.

2.3.2. Fixed-Time Method. Accurately measured aliquots $(0.05-1.0 \mathrm{~mL})$ of GMF $\left(100 \mu \mathrm{g} \mathrm{mL}^{-1}\right)$ standard solution and $(0.2-1.2 \mathrm{~mL})$ of MOX $\left(100 \mu \mathrm{g} \mathrm{m}^{-1}\right)$ standard solution were transferred into $10 \mathrm{~mL}$ calibrated volumetric flasks. Then $0.4 \mathrm{~mL}$ of borate buffer solution was added followed by 1.0 and $0.8 \mathrm{~mL}$ of NBD-Cl solution $\left(5.0 \times 10^{-3} \mathrm{M}\right)$ for GMF and MOX, respectively, and the volume was completed to the mark with $50 \%(\mathrm{v} / \mathrm{v})$ aqueous acetone, mixed well, and heated on water bath at $70 \pm 5^{\circ} \mathrm{C}$ for a fixed time of 20 and $15 \mathrm{~min}$ for GMF and MOX, respectively. After mixing, the contents of each flask were completed to $10 \mathrm{~mL}$ with $50 \%$ (v/v) aqueous acetone and immediately transferred to the spectrophotometric cell and the absorbance was recorded at 466 and $464 \mathrm{~nm}$ GMF and MOX, respectively, against reagent blank treated similarly. The calibration curve was constructed by plotting the absorbance against the final concentration of the drug. The amount of the drug in each sample was computed from the corresponding equation of the calibration graph for the fixed time method $(A=$ slope $C+$ intercept).

2.4. Procedure for Pharmaceutical Formulations. A total of 20 tablets of each drug were crushed and finely powdered. An accurately weighed quantity of the mixed contents of the tablets, equivalent to $100 \mathrm{mg}$ of the drug, was extracted into $50 \mathrm{~mL}$ of $0.005 \mathrm{M}$ hydrochloric acid solution, stirred for 15 minutes, and then filtered using Whatman no. 42 filter paper into a $100 \mathrm{~mL}$ volumetric flask to isolate the insoluble excipients. The residue was washed twice with $0.005 \mathrm{M}$ hydrochloric acid solution and washings were added to the filtrate and diluted to volume with the same solvent. Aliquots of the tablet solutions were treated as under the above recommended procedures. Determine the nominal content

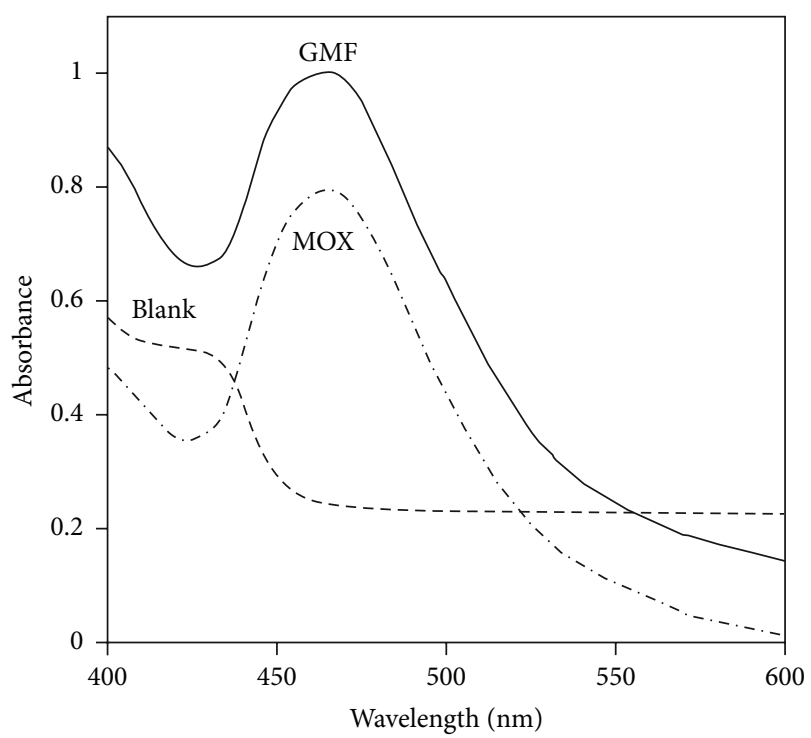

FIGURE 1: Absorption spectra of $8.0 \mu \mathrm{g} \mathrm{mL}^{-1} \mathrm{GMF}$ and $10 \mu \mathrm{g} \mathrm{mL}^{-1}$ MOX with NBD-Cl $\left(5.0 \times 10^{-3} \mathrm{M}\right)$ against reagent blank.

of the tablets either from a previously plotted calibration graph or using the corresponding regression equation.

2.5. Determination of Molar Ratio of the Reaction. Job's method of continuous variation [38] was employed. Master equimolar solutions $\left(5.0 \times 10^{-4} \mathrm{M}\right)$ of drugs and reagent were prepared. Series of $10 \mathrm{~mL}$ portions of the master solutions of the drugs and the analytical reagent were made up comprising different complementary ratios $(0: 10,1: 9,9: 1$, and $10: 0$, inclusive) in $10 \mathrm{~mL}$ calibrated flasks. The solutions were further manipulated as described under the general recommended procedure and data treatment.

\section{Results and Discussion}

3.1. Absorption Spectra. The reaction between the investigated drugs and NBD-Cl in slightly alkaline borate buffer produces an orange-yellow color with maximum absorbance at 466 and $464 \mathrm{~nm}$ for GMF and MOX, respectively (Figure 1). Different experimental parameters affecting the color development and its stability were carefully studied and optimized. Such factors were changed individually while keeping others constant. These factors include $\mathrm{pH}$ and volume of buffer, $\mathrm{NBD}-\mathrm{Cl}$ concentration, temperature, and solvent.

\subsection{Optimization of the Reaction Conditions}

3.2.1. The Effect of $p H$ and Volume of Buffer. The effect of $\mathrm{pH}$ change the absorbance was studied by using $0.1 \mathrm{M}$ borate buffer in the $\mathrm{pH}$ range 7.5-10. Below $\mathrm{pH} 7.0$, no color was formed. With increasing the $\mathrm{pH}$, higher absorbance values were obtained with maximum absorbance at $\mathrm{pH}$ values 9.0 and 8.5 for GMF and MOX, respectively, (Figure 2). At 


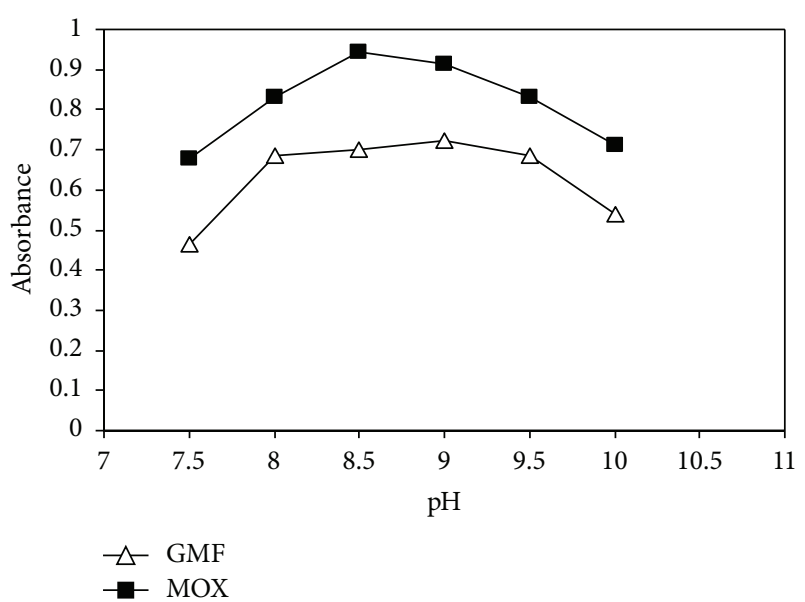

FIGURE 2: Effect of $\mathrm{pH}$ of borate buffer on the development of the reaction product of drugs with $\mathrm{NBD}-\mathrm{Cl}$ at optimum temperature and time.

higher $\mathrm{pH}$ values, the background absorbance of the reagent increased resulting in a net decrease in absorbance of the drug solutions. Other buffers having the same $\mathrm{pH}$ values such as phosphate buffer and citric acid phosphate (Mcllvaine's buffer) and weak bases such as $0.1 \mathrm{M}$ sodium bicarbonate were tried and compared with the $0.1 \mathrm{M}$ borate buffer. Borate buffer was found to be superior because it resulted in more stable highly colored solutions. The effect of the volume of borate buffer was studied and it was found that $0.4 \mathrm{~mL}$ was sufficient to get the highest color intensity.

3.2.2. The Effect of NBD-Cl Concentration. The most important factor affecting on the formation of reaction product was the concentration of NBD-Cl. The influence of the concentration of NBD-Cl was studied using different volumes of $\left(5.0 \times 10^{-3} \mathrm{M}\right) \mathrm{NBD}-\mathrm{Cl}$ solution. Figure 3 shows that 1.0 and $0.8 \mathrm{~mL}$ of $\left(5.0 \times 10^{-3} \mathrm{M}\right) \mathrm{NBD}-\mathrm{Cl}$ solution for GMF and MOX, respectively gave maximum sensitivity. Increasing the volume of NBD-Cl leads to the decrease in the absorbance; this may be due to the high background absorbance of the reagent.

3.2.3. The Effect of Temperature and Time. The effect of temperature was studied in the range of $30-90^{\circ} \mathrm{C}$ with constant heating time. Increasing the temperature of the water bath produced an increase in the reaction rate and consequently in absorbance of the reaction product up to $70 \pm 5^{\circ} \mathrm{C}$ for the two drugs, above which almost constant absorbance values were obtained. Therefore, $70^{\circ} \mathrm{C}$ was selected as the optimum temperature for both drugs (Figure 4). Heating at temperatures higher than $70 \pm 5^{\circ} \mathrm{C}$ resulted in slightly turbid solutions. In order to determine the optimum time required for the completion of the reaction, the derivatization reaction was carried in the range of 5.0-40 $\mathrm{min}$. Complete color development was attained after 20 and $15 \mathrm{~min}$ for GMF and MOX, respectively, in water bath at $70 \pm 5^{\circ} \mathrm{C}$.

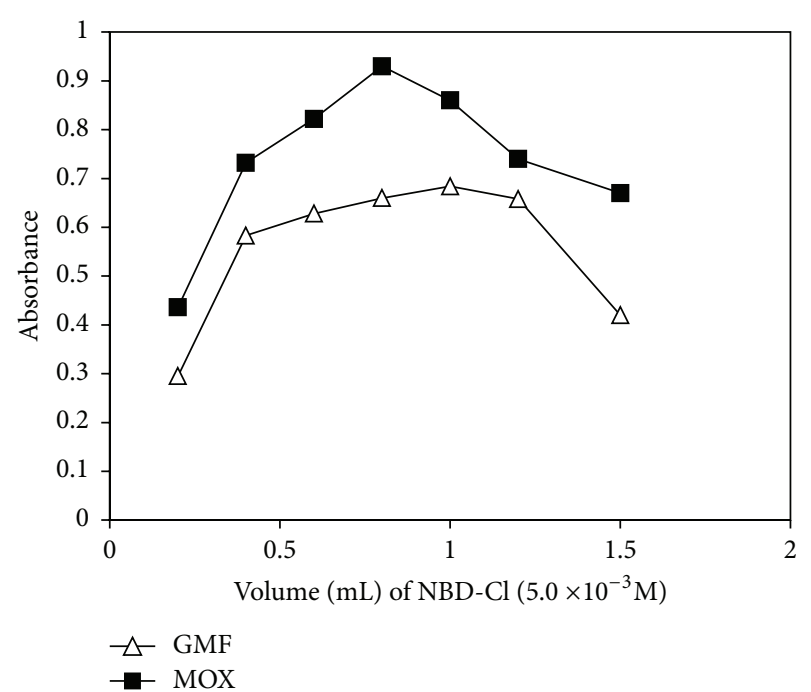

Figure 3: Effect of volume $(\mathrm{mL})$ of NBD-Cl $\left(5.0 \times 10^{-3} \mathrm{M}\right)$ on the development of the reaction product at optimum temperature and time.

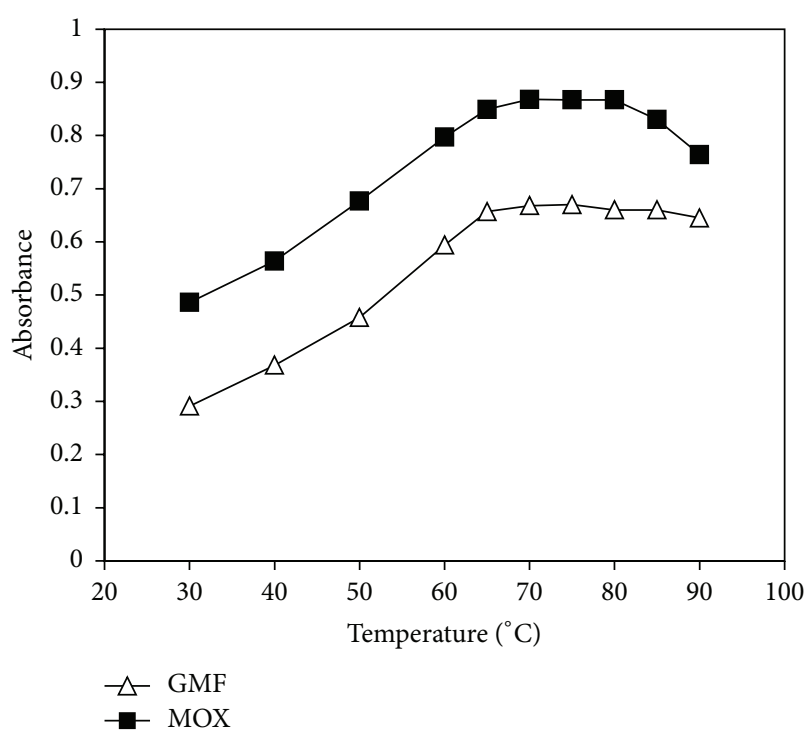

FIGURE 4: Effect of temperature on the formation of colored product drug-NBD-Cl, $(\mathrm{GMF})=8.0 \mu \mathrm{g} \mathrm{mL} \mathrm{m}^{-1}+1.0 \mathrm{~mL} \mathrm{NBD}-\mathrm{Cl}(5.0 \times$ $\left.10^{-3} \mathrm{M}\right)$ for $20 \mathrm{~min}$ and $(\mathrm{MOX})=12 \mu \mathrm{g} \mathrm{mL}^{-1}+0.8 \mathrm{~mL} \mathrm{NBD}-\mathrm{Cl}(5.0$ $\times 10^{-3} \mathrm{M}$ ) for $15 \mathrm{~min}$.

3.2.4. Effect of Solvent. Several diluting solvents were tested to determine the most appropriate solvent: methanol, acetone, dichloromethane, chloroform, and acetonitrile. Acetone was found to be the best solvent regarding sensitivity and the highest absorbance values. The effect of time on the stability of the drug-NBD-Cl derivative in acetone was studied at different time intervals. The color remains stable at least for $12 \mathrm{~h}$, while methanol caused about $50 \%$ decrease in sensitivity. The situation was much worse when distilled water was used because turbid solutions were obtained. A summary for the optimization of the variables affecting the reaction of both drugs with NBD-Cl is given in Table 3 . 
TABLE 3: Experimental and analytical parameters for the kinetic spectrophotometric determination of GMF and MOX.

\begin{tabular}{|c|c|c|}
\hline Parameter & GMF & MOX \\
\hline $\mathrm{pH}$ and volume of borate buffer & $\mathrm{pH} 9.0 / 0.4 \mathrm{~mL}$ & $\mathrm{pH} 8.5 / 0.4 \mathrm{~mL}$ \\
\hline Volume of $5.0 \times 10^{-3} \mathrm{M} \mathrm{NBD}-\mathrm{Cl}(\mathrm{mL})$ & 1.0 & 0.8 \\
\hline Temperature $\left({ }^{\circ} \mathrm{C}\right)$ & 70 & 70 \\
\hline Reaction time (min.) & 20 & 15 \\
\hline Solvent & $50 \%(\mathrm{v} / \mathrm{v})$ aqueous acetone & $50 \%(\mathrm{v} / \mathrm{v})$ aqueous acetone \\
\hline$\lambda_{\max }(\mathrm{nm})$ & 466 & 464 \\
\hline Concentration range $(\mathrm{M})$ & $1.029 \times 10^{-6}-1.65 \times 10^{-5}$ & $4.57 \times 10^{-6}-2.74 \times 10^{-5}$ \\
\hline Concentration range $\left(\mu \mathrm{g} \mathrm{mL}^{-1}\right)$ & $0.5-8.0$ & $2.0-12$ \\
\hline Molar absorptivity $(\varepsilon)\left(\mathrm{L} \mathrm{mol}^{-1} \mathrm{~cm}^{-1}\right)$ & $4.0892 \times 10^{4}$ & $3.48535 \times 10^{4}$ \\
\hline Sandell's sensitivity $\left(\mathrm{ng} \mathrm{cm}^{-2}\right)$ & 11.87 & 12.56 \\
\hline \multicolumn{3}{|l|}{ Regression equation ${ }^{\mathrm{a}}$} \\
\hline Slope & 0.0972 & 0.0802 \\
\hline Intercept & 0.0068 & -0.0039 \\
\hline Correlation coefficient $(r)$ & 0.9999 & 0.9998 \\
\hline $\operatorname{LOD}(\mathrm{M}),\left(\mu \mathrm{g} \mathrm{mL}^{-1}\right)$ & $2.47 \times 10^{-7},(0.12)$ & $8.22 \times 10^{-7},(0.36)$ \\
\hline LOQ $(\mathrm{M}),\left(\mu \mathrm{g} \mathrm{mL}^{-1}\right)$ & $8.24 \times 10^{-7},(0.4)$ & $2.74 \times 10^{-6},(1.2)$ \\
\hline Recovery $\% \pm$ SD & $100.03 \pm 0.87$ & $99.99 \pm 1.24$ \\
\hline RSD\% & 0.87 & 1.24 \\
\hline $\mathrm{RE} \%$ & 0.91 & 1.30 \\
\hline$t$-value $\mathrm{b}^{\mathrm{b}}$ & $0.21(2.57)$ & $0.38(2.78)$ \\
\hline$F$-value ${ }^{\mathrm{b}}$ & $2.03(5.05)$ & $2.07(5.19)$ \\
\hline
\end{tabular}

${ }^{\mathrm{a}} A=a+b C$, where $C$ is the concentration in $\mu \mathrm{g} \mathrm{mL}{ }^{-1}$.

${ }^{\mathrm{b}}$ Theoretical value for $t$ and $F$ at $95 \%$ confidence level at $P=0.05$.

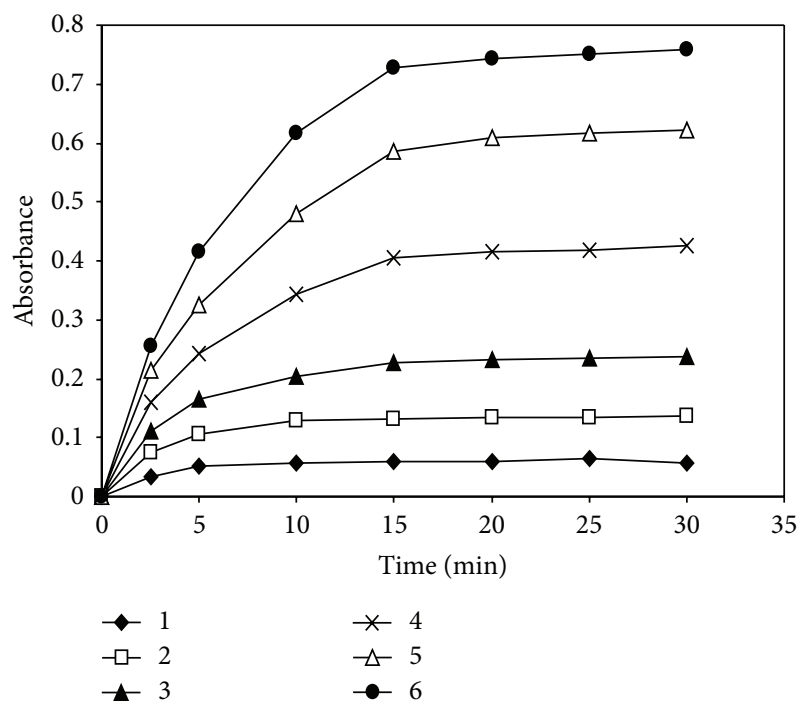

FIGURE 5: Absorbance versus time graphs for the reaction of GMF and NBD-Cl. Concentration of GMF: (1) $1.03 \times 10^{-6}$, (2) $2.06 \times 10^{-6}$, (3) $4.12 \times 10^{-6}$, (4) $8.24 \times 10^{-6}$, (5) $1.24 \times 10^{-5}$, (6) $1.65 \times 10^{-5} \mathrm{M}$.

3.3. Kinetics Study of the Reactions. The rate of reaction was found to be drug dependant. The rates were followed at $70 \pm 5^{\circ} \mathrm{C}$ with various concentrations of the investigated drugs in the range $1.029 \times 10^{-6}-1.65 \times 10^{-5} \mathrm{M}\left(0.5-8.0 \mu \mathrm{g} \mathrm{mL}^{-1}\right)$ for GMF and the range $4.57 \times 10^{-6}-2.74 \times 10^{-5} \mathrm{M}(2.0-$ $12 \mu \mathrm{g} \mathrm{mL}^{-1}$ ) for MOX, keeping NBD-Cl at the concentration

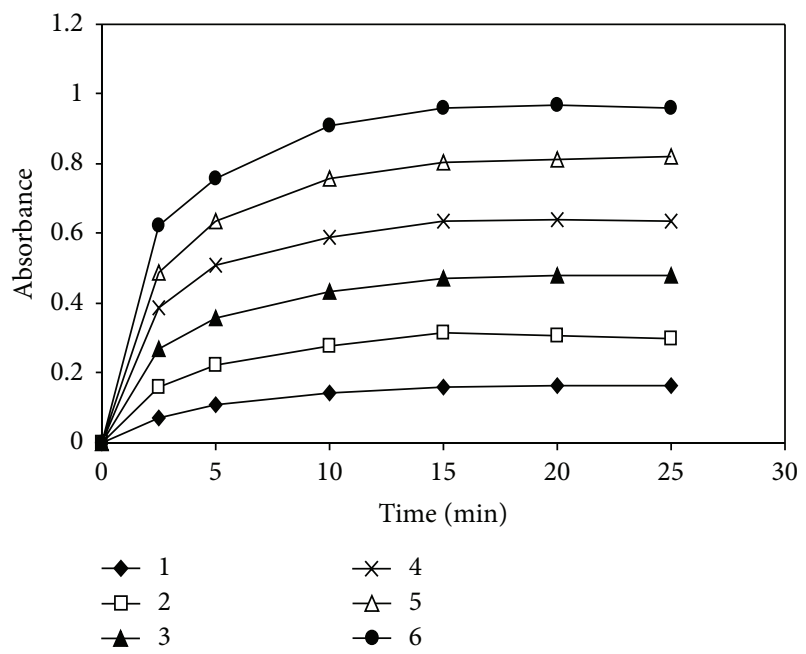

Figure 6: Absorbance versus time graphs for the reaction of MOX and NBD-Cl. Concentration of MOX: (1) $4.57 \times 10^{-6}$, (2) $9.14 \times 10^{-6}$, (3) $1.37 \times 10^{-5}$, (4) $1.83 \times 10^{-5}$, (5) $2.28 \times 10^{-5}$, (6) $2.74 \times 10^{-5} \mathrm{M}$.

stated above. The graphs shown in Figures 5 and 6 clearly indicate that the reaction rates obey the following equation:

$$
\text { Rate of the reaction }=\frac{\Delta A}{\Delta t}=K^{\prime}[C]^{n} \text {. }
$$

The rate of reactions could be estimated as $\Delta A / \Delta t$ [39], where $A$ is the absorbance, $t$ is the measuring time in seconds, $K^{\prime}$ is 


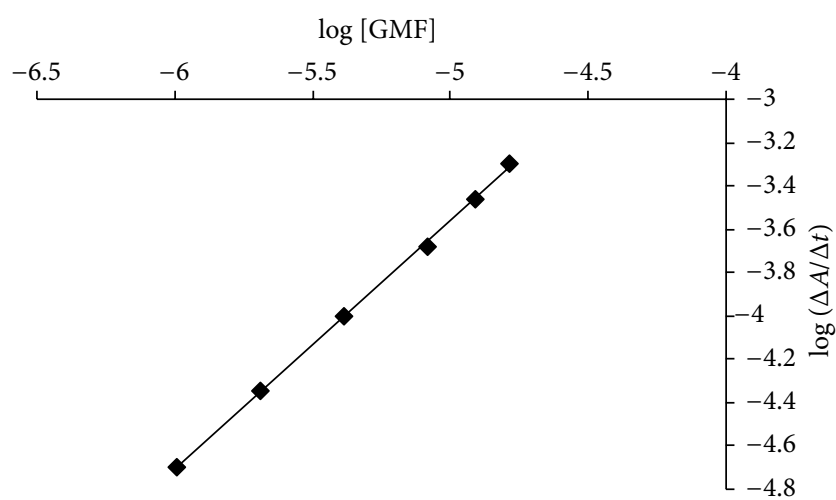

FIgURE 7: Calibration plot of logarithm rate of the reaction against logarithm molar concentration of GMF for rate data method.

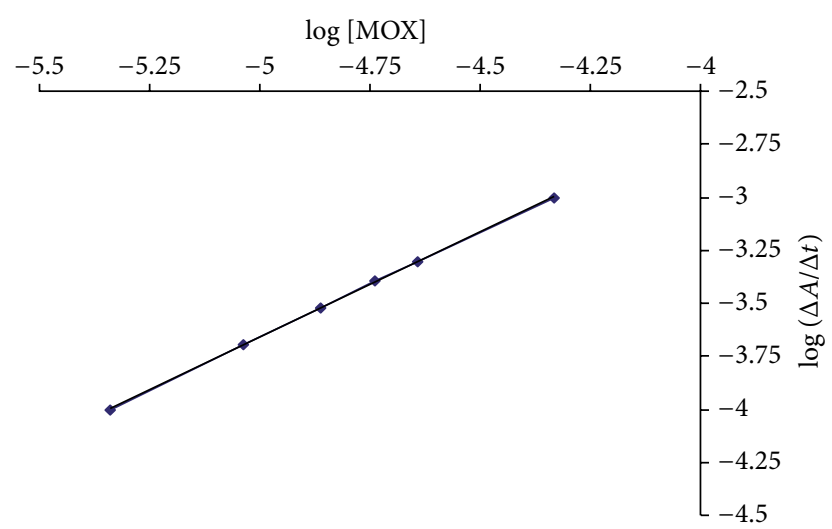

FIgURE 8: Calibration plot of logarithm rate of the reaction against logarithm molar concentration of MOX for rate data method.

the pseudo-order rate constant, $C$ is the concentration of the drug $\mathrm{mol} \mathrm{L}^{-1}$, and $\mathrm{n}$ is the order of reaction.

Taking logarithms of rates and concentrations, (1) is transformed into

$$
\log (\text { rate })=\log \frac{\Delta A}{\Delta t}=\log K^{\prime}+n \log [C] .
$$

A calibration curve was constructed by plotting the logarithm of the reaction rate $\log$ (rate) versus logarithm of drug concentration $\log [C]$ which showed a linear relationship (Figures 7 and 8). The logarithmic form of the above equation is written as follows:

$$
\begin{array}{r}
\log (\text { rate })=\log \frac{\Delta A}{\Delta t}=2.1602+1.1449 \log [\mathrm{GMF}], \\
r=0.9995, \\
\log (\text { rate })=\log \frac{\Delta A}{\Delta t}=0.9901+1.2901 \log [\mathrm{MOX}], \\
r=0.9999 .
\end{array}
$$

Hence $K^{\prime}=144.61 \mathrm{sec}^{-1}$ for GMF and $19.50 \mathrm{sec}^{-1}$ for MOX and the reaction is pseudo-first-order $(n \approx 1)$ with respect to either of the two drugs.
TABle 4: Values of rate constant $K^{\prime}$.

\begin{tabular}{lccc}
\hline$[\mathrm{GMF}] \mathrm{M}$ & $K^{\prime}\left(\mathrm{S}^{-1}\right)$ & {$[\mathrm{MOX}] \mathrm{M}$} & $K^{\prime}\left(\mathrm{S}^{-1}\right)$ \\
\hline $2.06 \times 10^{-6}$ & $-6.909 \times 10^{-4}$ & $4.57 \times 10^{-6}$ & $-2.303 \times 10^{-4}$ \\
$4.12 \times 10^{-6}$ & $-9.212 \times 10^{-4}$ & $9.14 \times 10^{-6}$ & $-4.606 \times 10^{-4}$ \\
$8.24 \times 10^{-6}$ & $-11.515 \times 10^{-4}$ & $1.37 \times 10^{-5}$ & $-6.909 \times 10^{-4}$ \\
$1.24 \times 10^{-5}$ & $-13.818 \times 10^{-4}$ & $1.83 \times 10^{-5}$ & $-9.212 \times 10^{-4}$ \\
$1.65 \times 10^{-5}$ & $-16.121 \times 10^{-4}$ & $2.28 \times 10^{-5}$ & $-11.515 \times 10^{-4}$ \\
& & $2.74 \times 10^{-5}$ & $-13.818 \times 10^{-4}$ \\
\hline
\end{tabular}

3.4. Evaluation of the Kinetic Methods. The determination of MOX and GMF under the optimized experimental conditions mentioned above, in which the NBD-Cl concentration was at least 30 times the concentration of GMF or at least 18 times the concentration of MOX, would result in pseudozero-order conditions with respect to NBD-Cl concentration and the rate of reaction will be directly proportional to the concentration of the drug in a pseudo-first-order rate equation as follows:

$$
\text { Rate }=K^{\prime}[C]
$$

where $K^{\prime}$ is the pseudo-first-order rate constant.

Equation (5) was the basis for several experiments, which were performed to obtain the drug concentration using the rate data. Initial rate, rate constant, fixed-concentration, and fixed-time methods [40] were tried and the most suitable analytical method was selected taking into account the applicability, sensitivity (i.e., the slope of the calibration graph), correlation coefficient $(r)$, and intercept $(a)$.

3.4.1. Initial-Rate Method. In this method, graphs of the rate (at the beginning of the reaction) versus drug concentration were not easy to obtain, because the first step of the reaction was too fast to follow, so tangents of the curve at zero-time were not easy to draw. Therefore, this method could not be applied.

3.4.2. Rate-Constant Method. The best way to obtain an average $K$ value for the reaction is to plot the logarithm of the concentration or the logarithm of any related property versus time. The slope of the line is $-K^{\prime} / 2.303$, from which the rate constant is obtained. If a straight line is obtained, it indicates that the reaction is first order. Graphs of log (absorbance) versus time over the concentration ranges $1.03 \times 10^{-6}-1.65 \times 10^{-5} \mathrm{M}\left(0.5-8.0 \mu \mathrm{g} \mathrm{mL}^{-1}\right)$ for GMF and $4.57 \times 10^{-6}-2.74 \times 10^{-5} \mathrm{M}\left(2.0-12 \mu \mathrm{g} \mathrm{mL}^{-1}\right)$ for MOX were plotted and all appeared to be rectilinear. Pseudo-first-order rate constants $\left(K^{\prime}\right)$ corresponding to different concentrations of the investigated drugs $[C]$ were calculated from the slopes multiplied by -2.303 (Table 4). Regression of $K^{\prime}$ versus [C] gave the following equations:

$$
\begin{array}{ll}
K^{\prime}=-6.0 \times 10^{-4}-61.258[\mathrm{GMF}], & (r=0.9876), \\
K^{\prime}=-7.0 \times 10^{-5}-45.191[\mathrm{MOX}], & (r=0.9889) .
\end{array}
$$


TABLE 5: Values of reciprocal time taken at fixed absorbance for the different rates of variable concentration of drugs at constant concentrations of NBD-Cl.

\begin{tabular}{lccc}
\hline$[\mathrm{GMF}] \mathrm{M}$ & $1 / t\left(\mathrm{~S}^{-1}\right)$ & {$[\mathrm{MOX}] \mathrm{M}$} & $1 / t\left(\mathrm{~S}^{-1}\right)$ \\
\hline $8.24 \times 10^{-6}$ & $2.02 \times 10^{-3}$ & $9.14 \times 10^{-6}$ & $1.19 \times 10^{-3}$ \\
$1.24 \times 10^{-5}$ & $3.70 \times 10^{-3}$ & $1.37 \times 10^{-5}$ & $4.76 \times 10^{-3}$ \\
$1.65 \times 10^{-5}$ & $5.13 \times 10^{-3}$ & $1.83 \times 10^{-5}$ & $8.33 \times 10^{-3}$ \\
& & $2.28 \times 10^{-5}$ & $1.11 \times 10^{-2}$ \\
& & $2.74 \times 10^{-5}$ & $1.38 \times 10^{-2}$ \\
\hline
\end{tabular}

The values of $(r)$ indicate poor linearity which is probably due to inconsistency of $K^{\prime}$ as a result of the inevitable slight changes in temperature of the reaction.

3.4.3. Fixed-Concentration Method. Reaction rates were determined for different concentrations of the investigated drugs. A preselected absorbance value was fixed $(0.3$ for both MOX and GMF) for different concentrations of the two drugs, in the range $8.24 \times 10^{-6}-1.65 \times 10^{-5} \mathrm{M}(4.0-$ $8.0 \mu \mathrm{g} \mathrm{mL}^{-1}$ ) for GMF and the range $9.14 \times 10^{-6}-2.74 \times 10^{-5} \mathrm{M}$ (4.0-12 $\mu \mathrm{g} \mathrm{mL}^{-1}$ ) for MOX, and the time required for each concentration to reach the preselected absorbance value was measured in seconds (Table 5). The reciprocal of time $(1 / t)$ was plotted versus the initial concentrations of the drug and the following equations were obtained by linear regression:

$$
\begin{array}{ll}
\frac{1}{t}=-9.0 \times 10^{-4}+366.87[\mathrm{GMF}], & r=0.9992, \\
\frac{1}{t}=-4.9 \times 10^{-3}+687.18[\mathrm{MOX}], & r=0.9990 .
\end{array}
$$

Although the correlation coefficient values are acceptable $(>0.999)$, the method still suffers from the narrow linearity ranges.

3.4.4. Fixed-Time Method. Reaction rates were determined for different concentrations of the studied drugs. At a preselected fixed time, which was accurately determined, the reaction was quenched by cooling and absorbance was measured. Calibration graphs of the absorbance $(A)$ versus initial concentration $[C]$ were established at different fixedtime intervals of 2.5-30 min. (Figures 6 and 7). At each fixed time, regression equation parameters were calculated and it was found that the slopes increase with time and the most acceptable values for the intercept and the correlation coefficient $(r)$ were obtained at a fixed time of $20 \mathrm{~min}$ for GMF and $15 \mathrm{~min}$ for MOX, which were therefore chosen as the most suitable time intervals for measurements. Calibration graphs were linear over the concentration ranges mentioned in Table 6.

3.5. Stoichiometric Ratio. The stoichiometry of the reaction was studied by adopting Job's method of continuous variation [38] for fixed-time method. Job's method plot reached maximum absorbance at a mole fraction of 0.5

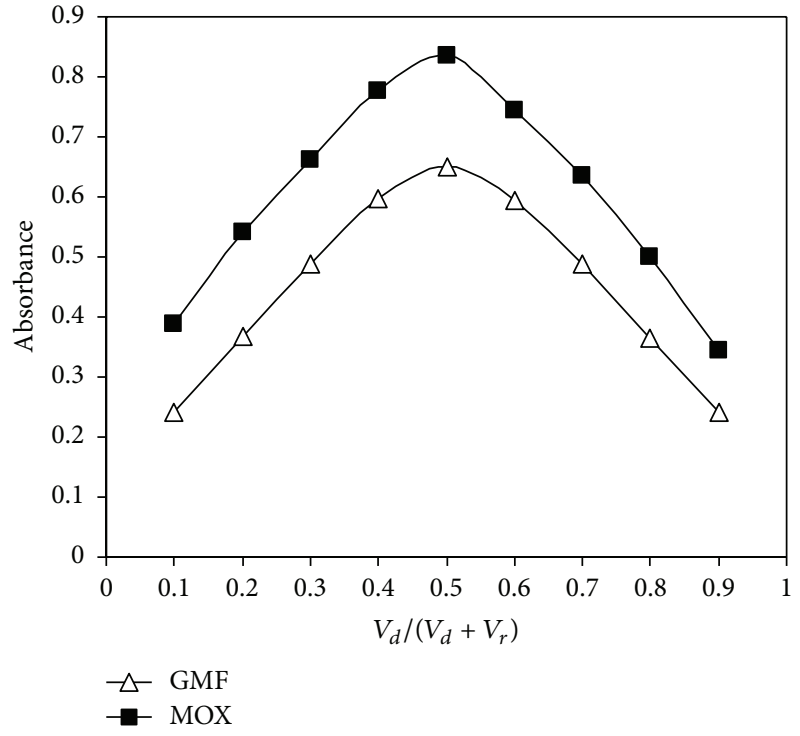

FIGURE 9: Job's method of continuous variations; $[\mathrm{D}]+[\mathrm{NBD}-\mathrm{Cl}]=$ $5.0 \times 10^{-4} \mathrm{M}$.

which indicated a reaction ratio of $1: 1$ (drug: $\mathrm{NBD}-\mathrm{Cl})$. The reaction mechanism can be explained by the formation of a Meisenheimer complex which is produced through a nucleophilic substitution reaction type. As presented in the following scheme, one molecule of NBD-Cl condenses with one molecule of the drug through its secondary aliphatic amino group (Figure 9).

3.6. Mechanism of the Color Reaction. N-Alkyl substituted tertiary amine fluoroquinolones such as ofloxacin and pefloxacin were found inactive towards NBD-Cl. Even $\alpha$ alkyl substituted secondary fluoroquinolone such as lomefloxacin gave weakly colored unstable products with NBD$\mathrm{Cl}$, possibly due to steric hindrance. Hence, NBD-Cl can be considered a selective reagent for the two studied drugs (GMF or MOX) among other fluoroquinolones of similar structure (Scheme 2).

\subsection{Validation of the Method}

3.7.1. Linearity. In the proposed method, linear plots with good correlation coefficients were obtained in the concentration ranges of $0.5-8.0$ and $2.0-12 \mu \mathrm{g} \mathrm{mL}^{-1}$ for GMF and MOX, respectively. Table 3 presents the performance data for the proposed spectrophotometric method, including molar absorptivities, Sandell's sensitivities, linearity ranges, and regression equations calculated from calibration graphs. Other statistical parameters such as the intercept $(a)$, the slope (b), and the relative standard deviation are also given in Table 3 . The high values of the correlation coefficients of the regression equations indicate good linearity over the working concentration ranges.

3.7.2. Detection and Quantitation Limits. In accordance with the recommendations of ICH [41], the limit of detection, 
TABLE 6: Regression equations for GMF and MOX at fixed time and $70 \pm 5^{\circ} \mathrm{C}$.

\begin{tabular}{lcccc}
\hline Time $(\mathrm{min})$ & $\begin{array}{c}\text { Regression equation } \\
\text { for GMF }\end{array}$ & $\begin{array}{c}\text { Correlation } \\
\text { coefficient }\end{array}$ & $\begin{array}{c}\text { Regression equation }{ }^{\mathrm{a}} \\
\text { for MOX }\end{array}$ & $\begin{array}{c}\text { Correlation } \\
\text { coefficient }\end{array}$ \\
\hline 2.5 & $A=0.0279 C+0.0419$ & 0.980 & $A=0.0552 C-0.053$ & 0.9967 \\
5 & $A=0.0723 C+0.0456$ & 0.9956 & $A=0.0662 C-0.0309$ & 0.9989 \\
10 & $A=0.0707 C+0.0552$ & 0.9990 & $A=0.0775 C-0.0236$ & 0.9992 \\
15 & $A=0.0911 C+0.0368$ & 0.9993 & $A=0.0802 C-0.0039$ & 0.9998 \\
20 & $A=0.0972 C+0.0068$ & 0.9999 & $A=0.0814 C-0.0083$ & 0.9994 \\
25 & $A=0.0958 C+0.0329$ & 0.9986 & $A=0.0815 C-0.0109$ & 0.9983 \\
30 & $A=0.0979 C+0.0318$ & 0.9990 & & \\
\hline
\end{tabular}

${ }^{\mathrm{a}} A$ : absorbance; $C$ : concentration.

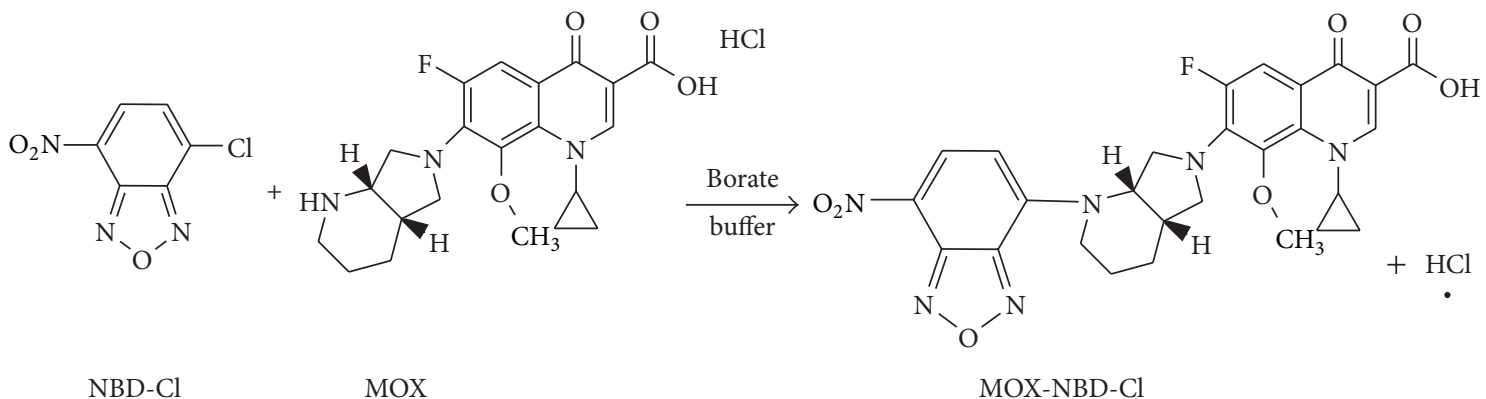

(a)<smiles>CO/N=C1\CCN(c2nc3c(cc2F)c(=O)c(C(=O)O)cn3C2CC2)CC1CN</smiles>

(b)

SCHEME 2: Proposed reaction pathways between NBD-Cl with (a) MOX at pH 8.5 and (b) GMF at pH 9.0 using borate buffer.

LOD, is $3.3 \sigma / \mathrm{s}$, where $\sigma$ is the standard deviation of replicate determinations of the blank and $s$ is the slope of the calibration graph. On the other hand, the limit of quantitation, LOQ, is defined as $10 \mathrm{\sigma} / \mathrm{s}$. The detection and quantitation limits of the two fluoroquinolones using the proposed spectrophotometric procedures are presented in Table 3. Obviously, the LOD and LOQ values as well as the concentration ranges are lower due to the higher sensitivity which is offered by this technique.

3.7.3. Accuracy and Precision. The accuracy and precision of the proposed methods were carried out by six replicate determinations at four different concentrations. Percentage relative standard deviation (RSD\%) as precision and percentage relative error (RE\%) as accuracy of the suggested method were calculated. Table 7 shows the values of relative standard deviations for different concentrations of the drugs determined from the calibration curves. These results of accuracy and precision show that the proposed methods have good repeatability and reproducibility. The proposed methods were found to be selective for the estimation of GMF and MOX in the presence of various tablet excipients. For this purpose, a powder blend using typical tablet excipients was prepared along with the drug and then analyzed. The recoveries were not affected by the excipients and the excipients blend did not show any absorption in the range of analysis. 
TABLE 7: Interday and intraday accuracy and precision for the determination of GMF and MOX in bulk powders by the proposed method (fixed time).

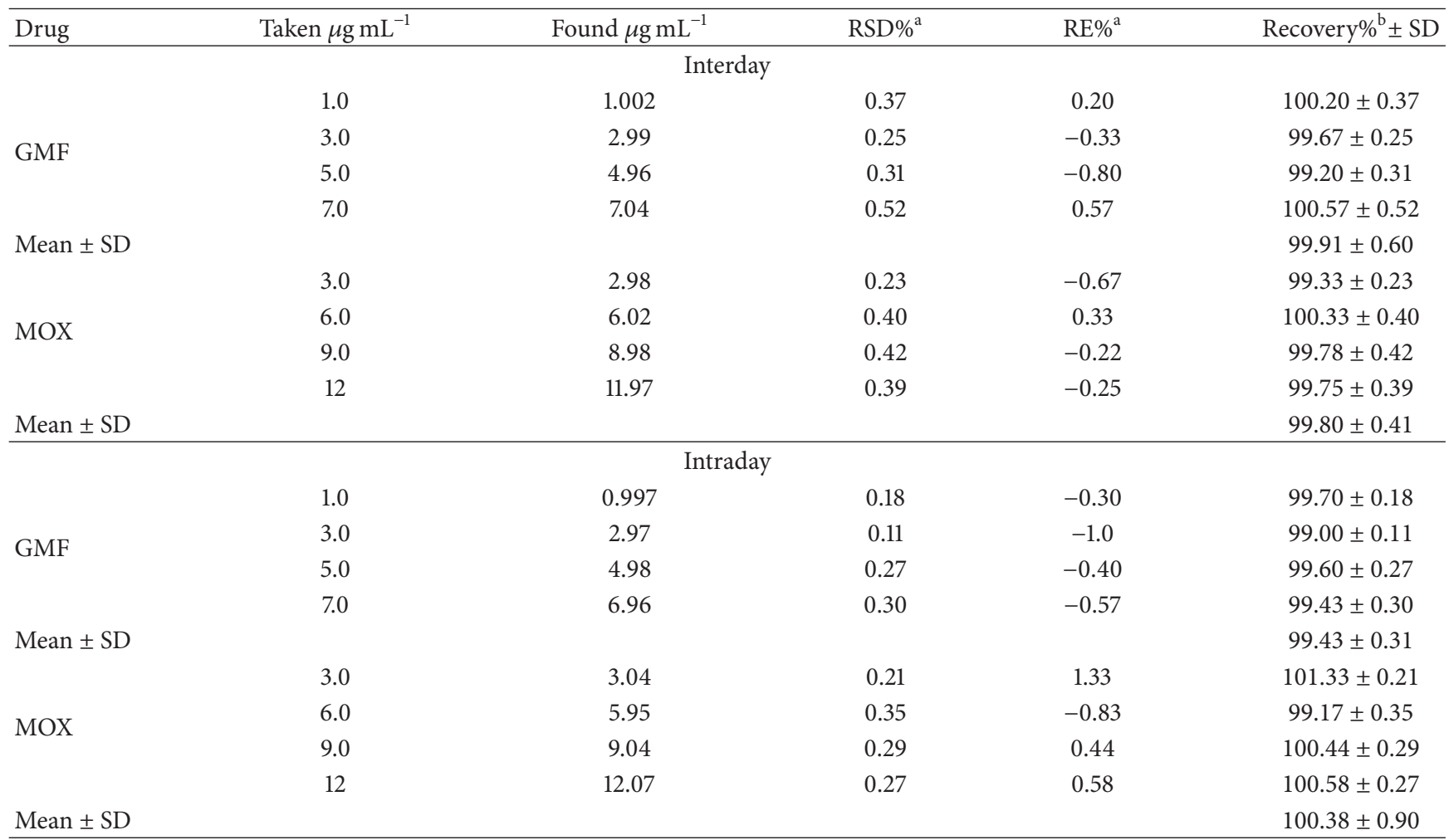

${ }^{a} \mathrm{RSD} \%$ : percentage relative standard deviation; RE\%: percentage relative error.

${ }^{\mathrm{b}}$ Average of six determinations.

3.7.4. Robustness and Ruggedness. The robustness of the proposed method was examined by evaluating the influence of small variation in the experimental variables on its analytical performance and that affect the absorbance values. In these experiments, one parameter was changed, whereas the others were kept unchanged, and the recovery percentage was calculated each time. It was found that small variation of the buffer $\mathrm{pH}$ by \pm 0.2 , heating temperature by $\pm 5^{\circ} \mathrm{C}$, and measurement wavelength by $\pm 2 \mathrm{~nm}$ did not significantly affect the spectrophotometric measurements; recovery values were 97.5-100.5 $\pm 1.3-1.9 \%$.

Ruggedness was also tested by applying the method to the assay of the studied drugs using the same operational conditions but using two different instruments at two different laboratories and different elapsed time. Results obtained from lab-to-lab and day-to-day variations were reproducible, as the RSD did not exceed 3.0\%.

3.8. Applications of Pharmaceutical Preparations. The proposed kinetic (fixed time) spectrophotometric method was applied to the determination of the studied drugs in their pharmaceutical formulations, including GMF (Flobiotic and GemiQue tablets) and MOX dosage forms (Avelox, Moxiflox, and Moxifloxacin tablets). Common tablet excipients did not interfere with the analysis. In addition, the proposed method enabled the determination of GMF and MOX in their dosage forms (tablets) without any interference from the inactive ingredients clearly whichdemonstrates the selectivity of the proposed methods.

Reference spectrophotometric methods for GMF [26] and MOX [36] were adopted for the assay of the studied drugs in dosage forms and the results were compared statistically with the proposed method with respect to the accuracy (by Student's $t$-test) and precision (by F-test) [42] (Table 8). No significant differences were found between the calculated and theoretical values of $t$ - and $F$-tests at 95\% confidence level proving similar accuracy and precision in the determination of the studied drugs by the proposed and reference methods.

\section{Conclusion}

Simple, sensitive, and selective kinetic fixed-time spectrophotometric procedure was developed for the analysis of the two fluoroquinolones: GMF and MOX. The simplicity, convenience at low cost, and sensitivity of the proposed method are superior or comparable to those of the reported methods and several previously published spectrophotometric methods. Also the reaction with $\mathrm{NBD}-\mathrm{Cl}$ is selective. The applicability of the developed methods was evaluated through 
TABLE 8: Application of the proposed methods for the determination of GMF and MOX in their pharmaceutical preparations.

\begin{tabular}{|c|c|c|}
\hline Sample & Proposed method & Reference methods ${ }^{\mathrm{c}}$ \\
\hline \multicolumn{3}{|c|}{ Factive tablets } \\
\hline$X \pm \mathrm{SD}^{\mathrm{a}}$ & $99.95 \pm 0.69$ & $100.08 \pm 0.56$ \\
\hline$t$-value ${ }^{\mathrm{b}}$ & 0.33 & \\
\hline$F$-value ${ }^{\mathrm{b}}$ & 1.52 & \\
\hline \multicolumn{3}{|c|}{ Flobiotic tablets } \\
\hline$X \pm \mathrm{SD}^{\mathrm{a}}$ & $100.05 \pm 0.74$ & $99.94 \pm 0.68$ \\
\hline$t$-value ${ }^{\mathrm{b}}$ & 0.24 & \\
\hline$F$-value ${ }^{\mathrm{b}}$ & 1.18 & \\
\hline \multicolumn{3}{|c|}{ GemiQue tablets } \\
\hline$X \pm \mathrm{SD}^{\mathrm{a}}$ & $99.90 \pm 0.72$ & $99.85 \pm 0.49$ \\
\hline$t$-value ${ }^{\mathrm{b}}$ & 0.13 & \\
\hline$F$-value ${ }^{\mathrm{b}}$ & 2.16 & \\
\hline \multicolumn{3}{|c|}{ Avelox tablets } \\
\hline$X \pm \mathrm{SD}^{\mathrm{a}}$ & $99.47 \pm 1.12$ & $99.03 \pm 0.97$ \\
\hline$t$-value ${ }^{\mathrm{b}}$ & 0.66 & \\
\hline$F$-value $^{\mathrm{b}}$ & 1.33 & \\
\hline \multicolumn{3}{|c|}{ Moxiflox tablets } \\
\hline$X \pm \mathrm{SD}^{\mathrm{a}}$ & $99.68 \pm 0.58$ & $99.34 \pm 0.34$ \\
\hline$t$-value ${ }^{\mathrm{b}}$ & 1.13 & \\
\hline$F$-value ${ }^{\mathrm{b}}$ & 2.91 & \\
\hline \multicolumn{3}{|c|}{ Moxifloxacin tablets } \\
\hline$X \pm \mathrm{SD}^{\mathrm{a}}$ & $99.80 \pm 0.87$ & $99.94 \pm 0.92$ \\
\hline$t$-value ${ }^{\mathrm{b}}$ & 0.25 & \\
\hline$F$-value ${ }^{\mathrm{b}}$ & 1.12 & \\
\hline
\end{tabular}

${ }^{\mathrm{a}}$ Mean for six independent analyses.

${ }^{\mathrm{b}}$ Theoretical values for $t$ - and $F$-values at five degrees of freedom and 95\% confidence limit are $(t=2.57)$ and $(F=5.05)$.

${ }^{c}$ Reference methods for GMF [26] and MOX [36].

the determination of the two drugs in bulk form and in pharmaceutical formulations with good accuracy and precision.

\section{Conflict of Interests}

The authors declare that there is no conflict of interests regarding the publication of this paper.

\section{References}

[1] S. C. Sweetman, Martindale: The Complete Drug Reference, Pharmaceutical Press, London, UK, 35th edition, 2011.

[2] M. J. O'Neil, The Merck Index: An Encyclopedia of Chemicals, Drugs and Biologicals, Merck, New York, NY, USA, 14th edition, 2006.

[3] B. M. H. Al-Hadiya, A. A. Khady, and G. A. E. Mostafa, "Validated liquid chromatographic-fluorescence method for the quantitation of gemifloxacin in human plasma," Talanta, vol. 83, no. 1, pp. 110-116, 2010.

[4] A. R. Rote and S. P. Pingle, "Reverse phase-HPLC and HPTLC methods for determination of gemifloxacin mesylate in human plasma," Journal of Chromatography B, vol. 877, no. 29, pp. 37193723, 2009.
[5] N. Sultana, M. S. Arayne, M. Akhtar, S. Shamim, S. Gul, and M. M. Khan, "High-performance liquid chromatography assay for moxifloxacin in bulk, pharmaceutical formulations and serum: application to in-vitro metal interactions," Journal of the Chinese Chemical Society, vol. 57, no. 4 A, pp. 708-717, 2010.

[6] M. Y. Salem, N. M. El-Guindi, H. K. Mikael, and L. E.-S. Abd-ElFattah, "Stability indicating methods for the determination of some fluoroquinolones in the presence of their decarboxylated degradates," Chemical and Pharmaceutical Bulletin, vol. 54, no. 12, pp. 1625-1632, 2006.

[7] A. F. Faria, M. V. N. de Souza, M. V. de Almeida, and M. A. L. de Oliveira, "Simultaneous separation of five fluoroquinolone antibiotics by capillary zone electrophoresis," Analytica Chimica Acta, vol. 579, no. 2, pp. 185-192, 2006.

[8] A. A. Elbashir, B. Saad, A. S. M. Ali, K. M. M. Al-Azzam, and H. Y. Aboul-Enein, "Validated stability indicating assay of gemifloxacin and lomefloxacin in tablet formulations by capillary electrophoresis," Journal of Liquid Chromatography and Related Technologies, vol. 31, no. 10, pp. 1465-1477, 2008.

[9] N. T. Abdel Ghani, M. A. El-Ries, and M. A. El-Shall, "Validated polarographic methods for the determination of certain antibacterial drugs," Analytical Sciences, vol. 23, no. 9, pp. 10531058, 2007.

[10] A.-E. Radi, T. Wahdan, Z. Anwar, and H. Mostafa, "Electrochemical and spectroscopic studies on the interaction of gatifloxacin, moxifloxacin and sparfloxacin with DNA and their analytical applications," Electroanalysis, vol. 22, no. 22, pp. 2665-2671, 2010.

[11] A.-E. Radi, T. Wahdan, Z. Anwar, and H. Mostafa, "Electrochemical determination of gatifloxacin, moxifloxacin and sparfloxacin fluoroquinolonic antibiotics on glassy carbon electrode in pharmaceutical formulations," Drug Testing and Analysis, vol. 2, no. 8, pp. 397-400, 2010.

[12] S. M. Al-Ghannam, "Atomic absorption spectroscopic, conductometric and colorimetric methods for determination of some fluoroquinolone antibacterials using ammonium reineckate," Spectrochimica Acta A, vol. 69, no. 4, pp. 1188-1194, 2008.

[13] H. Salem, "Spectrofluorimetric, atomic absorption spectrometric and spectrophotometric determination of some fluoroquinolones," American Journal of Applied Sciences, vol. 2, no. 3, pp. 719-729, 2005.

[14] S. E. K. Tekkeli and A. Önal, "Spectrofluorimetric methods for the determination of gemifloxacin in tablets and spiked plasma samples," Journal of Fluorescence, vol. 21, no. 3, pp. 1001-1007, 2011.

[15] S. T. Ulu, "Rapid and sensitive spectrofluorimetric determination of enrofloxacin, levofloxacin and ofloxacin with 2,3,5,6tetrachloro-p-benzoquinone," Spectrochimica Acta A, vol. 72, no. 5, pp. 1038-1042, 2009.

[16] J. Shah, R. Rasul Jan, I. Inayatullah, and N. Naeem Khan, "Micellar-enhanced spectrofluorometric quantification of moxifloxacin in pharmaceutical formulations, human urine and plasma samples," African Journal of Pharmacy and Pharmacology, vol. 5, no. 5, pp. 616-624, 2011.

[17] S. B. Wankhede, A. M. Mahajan, and S. S. Chitlange, "Simultaneous spectrophotometric estimation of gemifloxacin mesylate and ambroxol hydrochloride in tablets," Der Pharma Chemica, vol. 3, no. 1, pp. 269-273, 2011.

[18] R. I. EL-Bagary, N. F. Abo-talib, and M. B. N. Eldin, "Validated stability indicating assay of gemifloxacin by different chromatographic and spectrophotometric methods of analysis," Journal 
of Chemical and Pharmaceutical Research, vol. 3, no. 6, pp. 562570, 2011.

[19] D. C. Charan and S. Satyabrata, "Simple and rapid spectrophotometric estimation of gemifloxacin mesylate in bulk and tablet formulations," International Journal of PharmTech Research, vol. 3, no. 1, pp. 133-135, 2011.

[20] K. Hajera, "Development and validation of a dissolution test with spectrophotometric analysis for gemifloxacin in tablet dosage form," International Journal of Research in Pharmaceutical and Biomedical Sciences, vol. 3, no. 1, pp. 90-95, 2012.

[21] S. V. V. Dhanu Radha, K. M. C. Apparao, and K. Ramakrishna, "New visible spectrometric determination of gemifloxacin in its pure form," International Journal of Pharmacy and Pharmaceutical Sciences, vol. 4, pp. 618-621, 2012.

[22] V. Balaji, S. Poongothai, B. Madhavi et al., "Development and validation of adissolution test with spectrophotometric analysis for gemifloxacin in tablet dosage form," Pharma Science Monitor, vol. 2, no. 2, pp. S132-S145, 2010.

[23] M. V. Krishna and D. G. Sankar, "Utility of $\sigma$ and $\pi$-acceptors for the spectrophotometric determination of gemifloxacin mesylate in pharmaceutical formulations," E-Journal of Chemistry, vol. 5, no. 3, pp. 493-498, 2008.

[24] M. V. Krishna and D. G. Sankar, "Spectrophotometric determination of gemifloxacin mesylate in pharmaceutical formulations through ion-pair complex formation," E-Journal of Chemistry, vol. 5, no. 3, pp. 515-520, 2008.

[25] S. Ganapathy, G. V. H. Raju, D. G. Sankar, and P. Y. Naidu, "Spectrophotometric determination of gemifloxacin in bulk and pharmaceutical formulation," Asian Journal of Chemistry, vol. 21, no. 8, pp. 6508-6512, 2009.

[26] Z. Y. Al Shoaibi and A. A. Gouda, "Spectrophotometric methods for the determination of gemifloxacin mesylate in pure form and pharmaceutical formulations," Analytical Chemistry, vol. 9, 2010.

[27] M. Sugumaran, V. Meganathan, and T. Vetrichelvan, "Spectrophotometric method for the determination of Gemifloxacin mesylate in bulk and pharmaceutical formulations," Biosciences Biotechnology Research Asia, vol. 5, no. 1, pp. 495-496, 2008.

[28] D. Madhuri, K. B. Chandrasekhar, N. Devanna, and G. Somasekhar, "Direct and derivative spectrophotometric estimation of gemifloxacin by chelation with palladium(II) ion," Rasayan Journal of Chemistry, vol. 3, no. 1, pp. 159-165, 2010.

[29] D. M. Dhumal, A. A. Shirkhedkar, and S. J. Surana, "Quantitative determination of moxifloxacin hydrochloride in bulk and ophthalmic solution by UV-spectrophotometry and first order derivative using area under curve," Der Pharmacia Lettre, vol. 3, no. 3, pp. 453-456, 2011.

[30] M. Misra, A. K. Misra, P. Zope, G. M. Panpalia, and A. K. Dorle, "Simple and validated UV-spectroscopic method for estimation of moxifloxacin.HCL in bulk and formulation," Journal of Global Pharma Technology, vol. 2, no. 6, pp. 21-27, 2010.

[31] P. U. Patel, B. N. Suhagia, and M. M. Patel, "Spectrophotometric methods for estimation of moxifloxacin in pharmaceutical formulations," Indian Drugs, vol. 42, no. 10, pp. 654-657, 2005.

[32] A. Cirić, R. Jelić, L. Joksović, M. Jelikić-Stankov, and P. Djurdjević, "Determination of moxifloxacin in human plasma by derivative UV spectrophotometry in a micellar medium," Canadian Journal of Analytical Science and Spectroscopy, vol. 52, no. 6, pp. 343-350, 2007.

[33] S. K. Motwani, S. Chopra, F. J. Ahmad, and R. K. Khar, "Validated spectrophotometric methods for the estimation of moxifloxacin in bulk and pharmaceutical formulations," Spectrochimica Acta A, vol. 68, no. 2, pp. 250-256, 2007.

[34] M. A. Sultan, "New, simple and validated kinetics spectrophotometric method for determination of moxifloxacine in its pharmaceutical formulations," Arabian Journal of Chemistry, vol. 2, no. 2, pp. 79-85, 2009.

[35] D. R. Chaple and K. P. Bhusari, "Spectrophotometric estimation of fluroquinolones as ion-pairs with bromocresol green in bulk and pharmaceutical dosage form," Asian Journal of Chemistry, vol. 22, no. 4, pp. 2593-2598, 2010.

[36] L. M. Abdellaziz and M. M. Hosny, "Development and validation of spectrophotometric, atomic absorption and kinetic methods for determination of moxifloxacin hydrochloride," Analytical Chemistry Insights, vol. 6, no. 1, pp. 67-78, 2011.

[37] D. Pérez-Bendito, A. Gómez-Hens, and M. Silva, "Advances in drug analysis by kinetic methods," Journal of Pharmaceutical and Biomedical Analysis, vol. 14, no. 8-10, pp. 917-930, 1996.

[38] P. Job, Spectrochemical Methods of Analysis, Wiley Intersience, New York, NY, USA, 1971.

[39] F. Wilkinson and V. Nostrand, Chemical Kinetics and Reaction Mechanism, Rheihold Company, New York, NY, USA, 1980.

[40] D. Pérez-Bendito and M. Silva, Kinetic Methods in Analytical Chemistry, John Wiley and Sons, New York, NY, USA, 1988.

[41] International Conference on Harmonization of Technical Requirements for Registration of Pharmaceuticals for Human Use, ICH Harmonized Tripartite Guideline, Validation of Analytical Procedures: Text and Methodology, Q2(R 1), Complementary Guideline on Methodology dated 06 November 1996, ICH, London, UK, 2005.

[42] J. N. Miller and J. C. Miller, Statistics and Chemometrics for Analytical Chemistry, Prentice Hall, England, UK, 5th edition, 2005. 

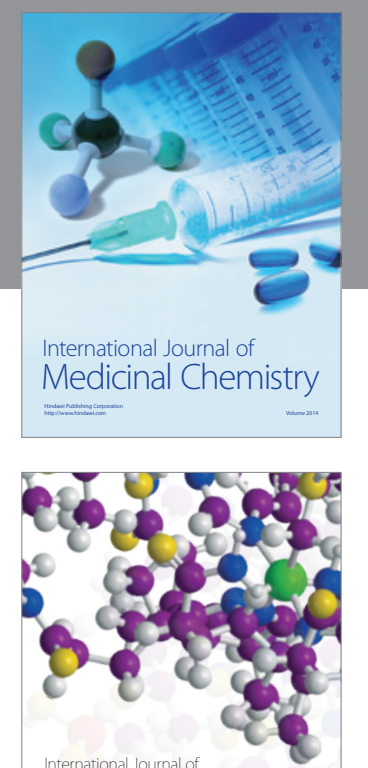

\section{Carbohydrate} Chemistry

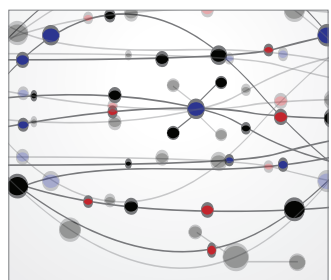

The Scientific World Journal
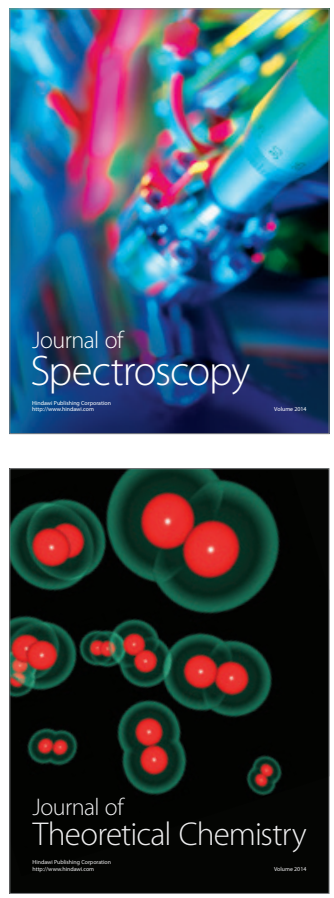
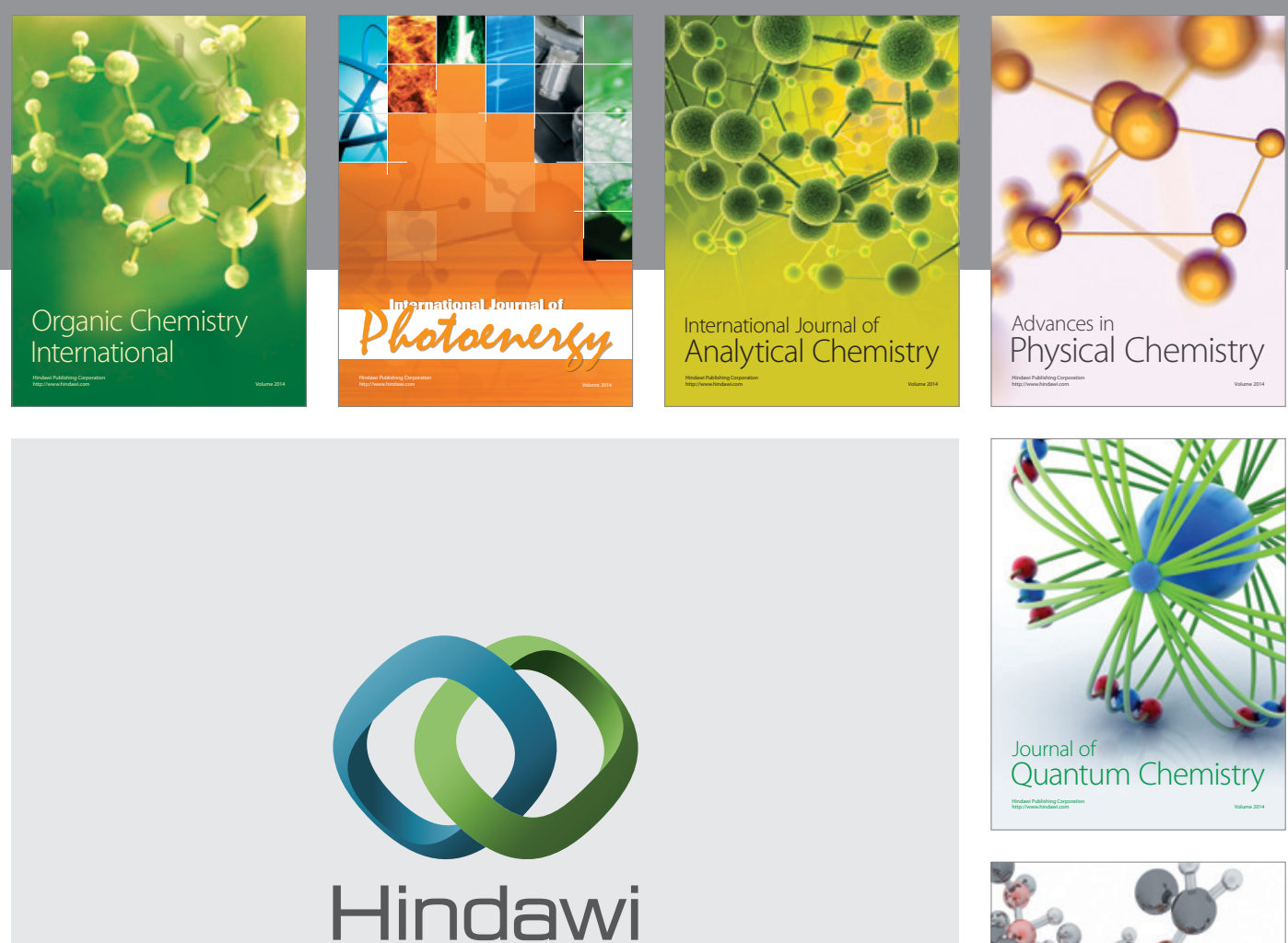

Submit your manuscripts at

http://www.hindawi.com

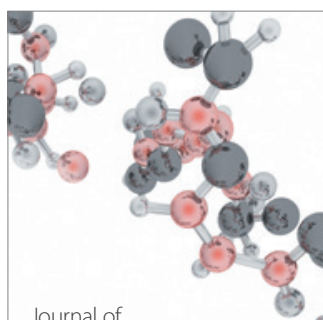

Analytical Methods

in Chemistry

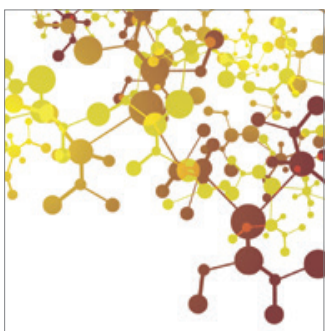

Journal of

Applied Chemistry

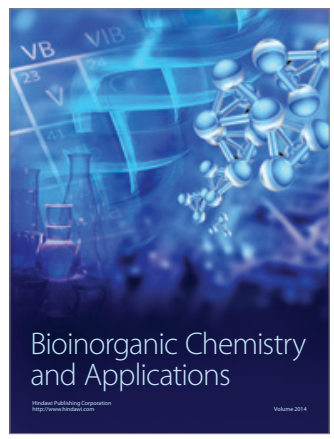

Inorganic Chemistry
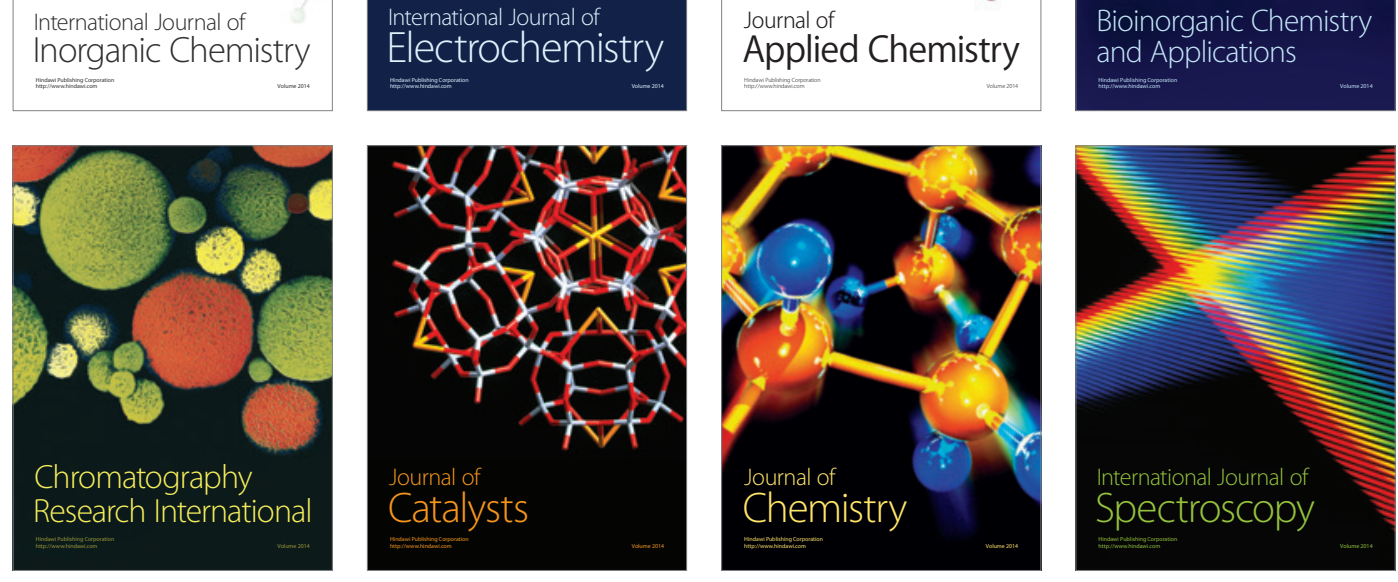